\title{
PBL English Teaching Research for Medical Postgraduates
}

\author{
Zeng Xiangfa ${ }^{1, \text { a }}$, Ren Mengmei ${ }^{2, b, ~ * ~}$ \\ ${ }^{1}$ English Teaching Department, Chengdu Medical College, Chengdu, Sichuan, China 610500 \\ ${ }^{2}$ English Teaching Department, Chengdu Medical College, Chengdu, Sichuan, China 610500
}

a1362806408@qq.com, b939567175@qq.com

Keywords: Medical postgraduate, PBL English teaching model.

\begin{abstract}
This study is to explore the effectiveness of PBL English teaching methods for medical postgraduates. PBL was used in medical postgraduates' English teaching and after the teaching, the students were surveyed and SPSS19.0 statistical software package was used for analysis. The results of statistical analysis found that medical postgraduate students' PBL English teaching model acceptance is 3.98, English learning interest 4.057, English learning attitude 3.65, and English learning outcome 3.77. Most of the medical postgraduates like PBL English teaching mode, which can greatly improve the interest of medical students in learning English and improve the students' oral English, listening and learning material collection and collation ability.

The teaching of English for medical postgraduates is a continuation of undergraduate English course. The purpose of teaching is to cultivate students with a better reading ability, a certain degree of writing, translation skills and basic listening and speaking abilities so that the medical postgraduates can use English as a tool to carry out the professional study and research. Medical postgraduate students are from all over the country, and the students are of different education background with uneven levels of English, they "do not understand English, cannot speak or write English", and there is still quite a gap between their English level and the actual application ${ }^{[1]}$. Li Shujing and others found that the purpose of graduate students in learning English is more realistic, mainly reflected in "external requirements motivation" and "communication media motivation". The students desire to obtain application skills, especially output oral and writing skills through questionnaire survey ${ }^{[2]}$. Many medical graduate students' English learning motivation is to access medical literature, professional information, writing and publishing SCI papers. However, most of current postgraduate English courses are mainly concentrated in traditional English classroom with similar teaching content and teaching methods to undergraduate teaching. Teachers mainly focus on vocabulary, grammar, and text structure. This teaching model not only cannot significantly improve the students' English level, but also has a certain hindrance to the formation of students' English thinking. Over time, medical graduate students are easy to lose interest in English learning ${ }^{[3]}$. In addition, compared to undergraduate, postgraduate students will not be affected by English level examinations, and students are prone to be inactive in English class and inattentive and so on ${ }^{[4]}$. In order to improve the interest of English in medical students and improve the comprehension abilities of English listening, speaking, reading, writing and translation of medical students, we will introduce PBL teaching model in medical postgraduates' English teaching to give a new perspective to supplement and expand graduate students' English teaching research to a certain extent.
\end{abstract}

\section{Subjects and methods}

The research subjects are 2016 and 2017 grade medical postgraduate students in our school. According to the principle of heterogeneous grouping, students in different levels were divided into groups according to "In-group heterogeneity, Inter-group homogeneity" based on students' differences in gender, personality, achievement, learning ability and behavior habit. The students 
were divided into several groups with a group of six $^{[5]}$. PBL teaching is implemented in teaching practice. Students study each unit articles in advance, and discuss the content of the text in groups. According to the text content, students put forward questions, and then teachers and students discuss them. After school, students prepare for the agreed questions, and present their achievements in the next class through PPT, speech and other forms. Finally, the teacher evaluates the student's presentation. At the end of whole teaching phase, a questionnaire on the teaching effect of PBL teaching model was distributed to the students, and SPSS19.0 software was used to analyze the data of all the subjects.

The questionnaire was prepared by using the questionnaire designed by Miao Zhangyan and revised appropriately. A total of 22 questionnaires were searched, and medical students' English learning attitude, learning motivation, learning ability, cooperative learning and autonomous learning were investigated. Each question uses Likert-type five-level scale: "totally agree", "agree", "not necessarily", "disagree", "totally disagree" five answers, respectively, as 5,4,3, 2,1 points. A total of 85 questionnaires were distributed to subjects and 82 valid questionnaires were retrieved and the recovery rate was $96.47 \%$.

\section{Results}

\section{A. Investigation of medical postgraduates' English learning motivation}

The questionnaire shows that $85.6 \%$ of the students study English for the purpose of publishing research papers; $72.8 \%$ of the medical postgraduate students study English to find a better job; 63.7\% of the medical postgraduate students study English because of interest; $62.4 \%$ of the medical postgraduate students study English for international academic exchanges; $40.3 \%$ of the medical postgraduate students study English for the country's future; $38.2 \%$ of the medical postgraduate students study English for doctoral examination; 35.2\% of the medical post graduate students study English in order to get higher test scores; 32.1\% of the medical postgraduate students study English to study abroad; $20.6 \%$ of the medical postgraduates study English for graduation, and only 8.3\% of the medical postgraduate students study English for the happiness of the family (see Figure 1).

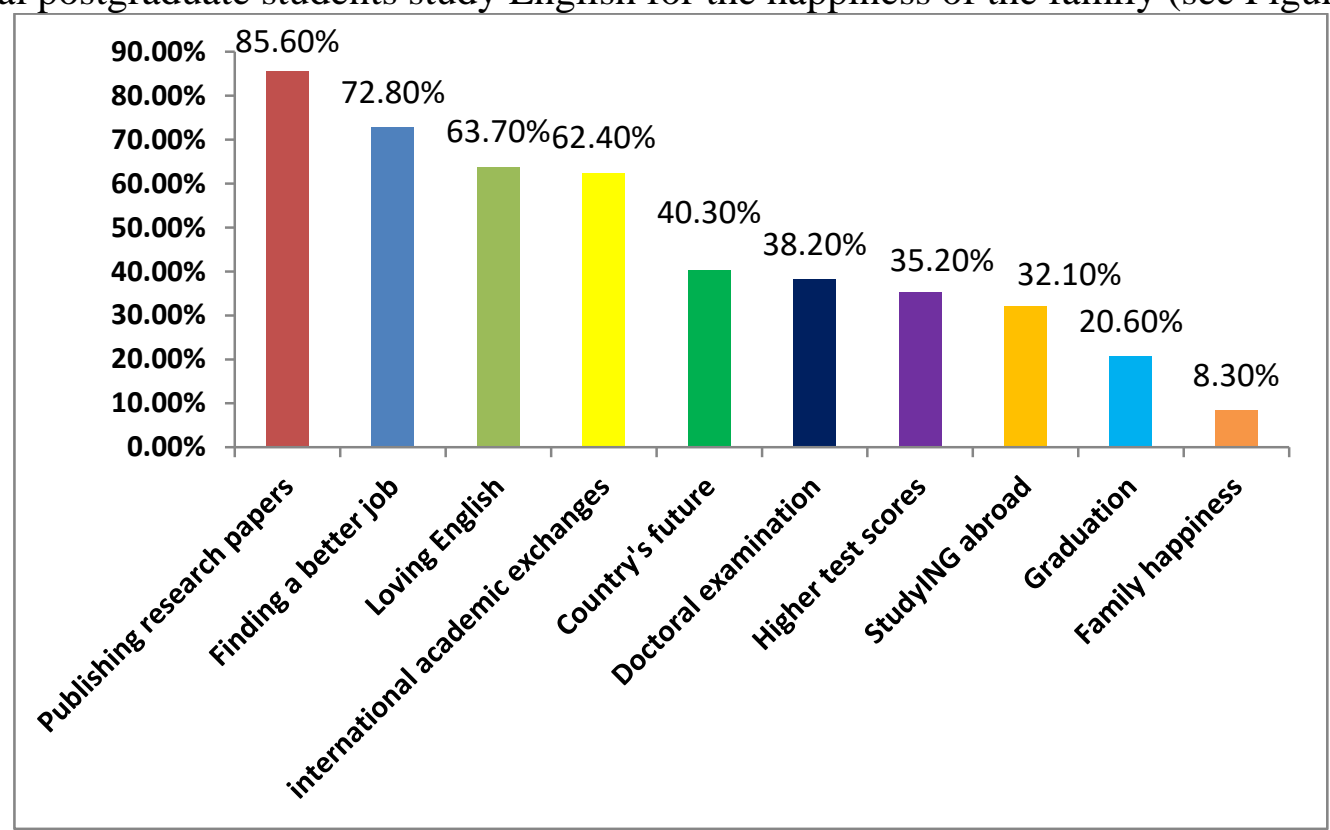

Figure 1 Medical Postgraduates’ English Learning Motivation

\section{B. Medical postgraduate students' attitude to PBL teaching model}

The overall attitude of medical postgraduate students to PBL English teaching model is shown in Table 1. As can be seen from Table 1, students give an average of 3.98 for three items in PBL teaching model, which is close to 4, especially students think cooperative learning is very important (Question 4) in PBL model, and the average is 4.02. Medical postgraduate students are very receptive to $\mathrm{PBL}$ teaching model. 
Table 1 Medical postgraduate students’ PBL teaching model attitude table

\begin{tabular}{lccccc} 
Category & Question Item & The Lowest Point & The Highest Point & Mean & The Standard Deviation \\
\hline Teaching & 4 & 2 & 5 & 4.02 & 0.801 \\
Method & 6 & 2 & 5 & 3.84 & 0.987 \\
& 7 & 2 & 5 & 3.94 & 0.934 \\
\hline Total & 3 & 1.67 & 5 & 3.98 & 0.907 \\
\hline
\end{tabular}

\section{Medical postgraduate students' English interest and attitude survey}

The survey result of medical postgraduate students' English learning interest under PBL teaching model is in Table 2, and medical postgraduate students' English learning attitude is in Table 3. Table 2 reflects that medical graduate students have strong learning interest in English PBL teaching model, and their English learning interest related items reach an average of 4.057, and many students want to learn English (Question 13), with an average of 4.70; postgraduate students want to speak English as much as possible (Question 8), with an average of 4.18; medical postgraduate students have a strong desire to learn English (Questions 11 and 17), with an average of 4.11.

Table 2 Medical postgraduate students’ English learning interest statistics table

\begin{tabular}{cccccc}
\hline Category & Question Item & The Lowest Point & The Highest Point & Mean & The Standard Deviation \\
\hline \multirow{4}{*}{ Study } & 2 & 1 & 5 & 3.80 & 0.949 \\
& 8 & 2 & 5 & 4.18 & 0.877 \\
Interest & 11 & 2 & 5 & 4.11 & 0.832 \\
& 12 & 1 & 5 & 3.44 & 0.918 \\
& 13 & 3 & 5 & 4.70 & 0.581 \\
Total & 17 & 2 & 5 & 4.11 & 0.846 \\
\hline
\end{tabular}

Table 3 reflects that medical students have more positive attitude in PBL English teaching model, and the average score of the relative items is 3.65. But medical students spend less time learning English (Question 16), with an average score of 2.85.

Table 3 Medical postgraduate students’ English learning attitude statistics table

\begin{tabular}{cccccc}
\hline Category & Question Item & The Lowest Point & The Highest Point & Mean & The Standard Deviation \\
\hline \multirow{5}{*}{ Study } & 2 & 1 & 5 & 3.80 & 0.949 \\
& 8 & 2 & 5 & 4.18 & 0.877 \\
Interest & 11 & 2 & 5 & 4.11 & 0.832 \\
& 12 & 1 & 5 & 3.44 & 0.918 \\
& 13 & 3 & 5 & 4.70 & 0.581 \\
\hline Total & 17 & 2 & 5 & 4.11 & 0.846 \\
\hline
\end{tabular}

\section{An investigation on the interests and attitudes of medical postgraduates in English learning}

PBL teaching effect is ideal in medical postgraduate students' English learning, and the average score is 3.77 points. Among them, medical students' oral English and listening comprehension are more obvious (Question18 and 20), with respective scores 3.93 and 3.96; at the same time, medical students' abilities in collecting and organizing their own English data also have more obvious improvements (Question 22), with 3.95. However, when the teacher asks questions, medical students answer questions without enough confidence (Question 15), score of 3.32 points, which is the lowest point in the six question items. 
Table 4 Medical postgraduate students’ English learning results table

\begin{tabular}{cccccc}
\hline Category & Question Item & The Lowest Point & The Highest Point & Mean & The Standard Deviation \\
\hline \multirow{5}{*}{ Study } & 2 & 1 & 5 & 3.80 & 0.949 \\
& 8 & 2 & 5 & 4.18 & 0.877 \\
Interest & 11 & 2 & 5 & 4.11 & 0.832 \\
& 12 & 1 & 5 & 3.44 & 0.918 \\
& 13 & 3 & 5 & 4.70 & 0.581 \\
Total & 17 & 2 & 5 & 4.11 & 0.846 \\
\hline
\end{tabular}

\section{Discussion}

There are seven types of postgraduate students’ English learning motivation: internal interests, learning context, personal development, overseas study, communication media, external requirements and academic performance. But for non-985, 211 medical colleges and universities, medical postgraduate students have to publish thesis and find satisfactory jobs, which is the most urgent task, and many medical college medical students are trying to get master's degree or get Master of academic degree to improve their employment chips, and stand out in the fierce employment competition. At the same time, to obtain better test scores and smooth graduation is no longer a problem for medical graduate students. As long as they finish seriously the training programs according to the instructor's instruction, they can successfully graduate.

The statistics in Table 1 show that most medical postgraduate students like PBL teaching model, which mainly relates with general college English teaching model and PBL teaching model characteristics. Most college English teaching is "teacher-centered" indoctrination teaching with low student participation. Medical postgraduate students are more offensive to this traditional way of teaching. In ordinary medical college, postgraduate students have short learning time in basic courses, long clinical study time with heavy learning tasks and less English classes. The essence of PBL teaching method is to focus on the problems, play the guiding role of problems in learning process, and mobilize students' initiative and enthusiasm in the process of participation. Table 2 statistics reflect that medical postgraduate students are highly interested in English learning. PBL teaching further improves the enthusiasm of medical postgraduate students in English learning, and many students also recognize the importance of learning English, which is very important to students' future work and research.

Although medical postgraduate students have strong interest and motivation in English learning, in the face of brutal reality of heavy learning tasks and less English learning class, the time spent on English learning is not enough (see Table 3), and postgraduate English study time input scores (2.85 points) the lowest, which seems "powerless" to them. Medical postgraduate students have less investment in English learning, but through classroom English PBL teaching, problems are taken as the main axis to play the main role of students in learning. Through various forms of group learning and self-learning, medical postgraduates' metacognitive capability as well as abilities to use specific knowledge and their communication skills are trained. And at the same time medical postgraduates' oral English ability, listening ability and data collection ability have been greatly improved (see Table 4). According to the theory of constructivism, learners form, enrich and adjust their cognitive structure of the process through the interaction of new and old knowledge and experience. On the one hand, learners combine new knowledge into the existing cognitive structure and access to new meaning; on the other hand, the original knowledge and experience get a certain adjustment or reorganize because of the incorporation of new knowledge. And to integrate inquiry-based learning and cooperative learning based on Constructivism Theory with medical graduate students PBL English teaching model fully, students take the initiative to participate in and to experience, and through the cooperation between team members and teachers and students' interaction, students' English language ability continues to improve. PBL teaching not only allows students to achieve the purpose of communication in English, but also enhances their level of daily communication ${ }^{[7]}$. According to language input hypothesis of second language acquisition expert Krashen and Merrill 
Swain's language output hypothesis, medical postgraduate students get a large number of English language conscious input in the process of learning process and discussing materials and make English language output in group discussion and learning results show in order to achieve their own language ability improvement.

However, medical postgraduate students are not enough confident to speak in English PBL teaching (see Table 4 questionnaire 15), which is mainly because that medical students developed "dumb" English habits in middle school, and they are influenced by traditional Chinese introverted personality characteristics, which need further work in the future.

\section{Conclusion}

Through PBL teaching practice of two grades' medical postgraduate students, questionnaire survey was conducted with self-compiled questionnaire. It was found that medical postgraduate students preferred PBL English teaching and it could improve medical postgraduate students' oral English, listening and material collection ability in group cooperative learning and autonomous learning activities. In order to improve the ability of English learning and language comprehensive use, medical students have to invest more time to complete preview and review tasks, and teachers should get more teaching time. PBL English model is a better graduate teaching model.

\section{Acknowledgements}

The work was supported by Sichuan Provincial Foreign Language Literature Research Center Fund (No.: SCWYH17-05).

\section{References}

[1] Zhou Weiwei, Sun Qiyao. Postgraduate English teaching status and talent training trend analysis [J]. Continuing Education Research, 2017, (09): 109-111.

[2] Li Shujing, Gao Yihong, Qian Min. Postgraduate English learning motivation [J]. Journal of PLA Foreign Languages Institute, 2003, (02): 63-68.

[3] Zhang Hu, Meng Jun, He Jianchao, Tao Jie, Bai Xiangfeng. CBL teaching method in medical graduate professional English teaching application $[\mathrm{J}]$. Chinese Journal of continuing medical education, 2017,9 (09): 17-19.

[4] Chen Hua, Li Aihua. Several important factors' status quo analysis and countermeasures in medical English teaching [J]. Shanxi Medical University Journal (Basic Medical Education Edition), 2002,4 (03): 187-188.

[5] Hu Shuangquan. Cooperative learning in postgraduate English teaching application [J].

[6] Miu Zhangyan. Application of PBL in college English teaching. Anhui University .2014.05.

[7] Yu Changqing, Huang Ying. PBL enlightenment in graduate English teaching practice [J]. Education observation (late), 2015, 4 (05): 60-62. 